Riitta Holopainen, Leena Järveläinen, Päivikki Karhula, Eeva Savolainen ja Minna Suikka

\title{
VIDEOIDEN TEKSTITYSTYÖKALUT VERTAILUSSA
}

Laki edellyttää julkisilta organisaatioilta saavutettavuusvaatimusten täyttämistä. Yhä useammin kirjastonkin tuottama koulutustuokio tai ohje julkaistaan videona, joka on saavutettavuusvaatimusten mukaan tekstitettävä. Mitä jokaisen videontekijän on syytä tietää tekstittämisestä? Miten löytää toimivin ja yksinkertaisin työkalu erilaisten ohjelmien viidakosta? Onko teknologia kehittynyt jo niin pitkälle, että tekstitys hoituu automaattisen puheentunnistuksen avulla? Tässä artikkelissa lyömme haarukkamme digipalvelujen tuottamisen kuumaan perunaan vertailemalla videoiden tekstittämiseen tarjolla olevia työkaluja.

V ideoiden tekstitystä koskeva vaatimus saattaa tuntua videoiden tuottajista tuskastuttavalta lisätyöltä. Tekstittäminen ei kuitenkaan ole vain lain noudattamista, vaan tekstityksestä on monia hyötyjä käyttäjille. Tekstitys avaa videoiden sisällöt niille, joilla on kuulossa rajoitteita, ja avustaa ei-äidinkielisiä käyttäjiä. Tekstit parantavat videoiden laatua ja käyttömukavuutta kaikkien käyttäjien näkökulmasta: ne tukevat vaikeaselkoisen puheen ymmärtämistä ja mahdollistavat videon katselun meluisassakin ympäristössä.

Milloin video sitten tulee tekstittää? Hyvä muistisääntö: tekstitä kaikki uudet, avoimessa verkossa julkaistavat videot. Helpotusta tuo se, että ennen 23.9. 2020 julkaistuja videoita ei tarvitse tekstittää takautuvasti. Lain saavutettavuusvaatimukset eivät koske myöskään suoria videolähetyksiä, mutta tallenne on tekstitettävä I 4 vuorokauden kuluessa julkaisemisesta. On kuitenkin suositeltavaa, että videotallenne on saavutettava jo julkaistaessa.

Yksi saavutettavuusvaatimuksia koskeva poikkeus liittyy opetussisältöihin, joiden käyttö tapahtuu rajatussa ryhmässä määräaikaisesti. Opetusvideoiden tekstittämistä koskeva ohjeistus kannattaa kuitenkin varmuuden vuoksi tarkistaa omasta organisaatiosta. Suositeltavaa on, että opetusvideoissa olisi tekstitykset, sillä ne edistävät videon saavutettavuutta ja käytettävyyttä.

\section{Millaiset tekstitykset videoon?}

Tekstitys muodostaa kirjallisen vastineen videolla puhutulle. Saavutettavuuden vuoksi tulisi tekstittää myös muut ymmärtämisen kannalta olennaiset äänet, mutta kaikkea ääniraidalla kuuluvaa ei tarvitse tekstittää. Tekstitys ei ole puhutun litterointia, vaan puhuttua voi myös tiivistää ja selkeyttää. Tekstityksen tärkein tehtävä on, että sitä seuraava saa saman in- 
formaation kuin puhetta kuunteleva.

Saavutettavuusvaatimukset edellyttävät, että tekstityksen kieli on sama kuin videolla puhuttu kieli. Suomenkielinen video tekstitetään suomeksi, englanninkielinen englanniksi. Sen sijaan saavutettavuusvaatimukset eivät määritä, millä tekniikalla tai työkalulla tekstitykset on tehtävä. Yleisesti suosituksena on closed captions -tekniikka, koska se antaa enemmän valinnanvaraa käyttäjälle: tekstitykset julkaistaan erillisenä tekstitystiedostona, ja käyttäjä voi laittaa tekstityksen päälle tai pois videota katsoessaan. Open captions -tekniikassa tekstitys on päällä koko ajan, koska se on poltettu kiinni videokuvaan.

Tekstittäminen kannattaa ottaa huomioon videon suunnittelussa alusta alkaen. Tällöin tekstitykset ovat linjassa käytettyjen työkalujen ja julkaisualustan kanssa, ja tekstittäjä välttyy ylimääräseltä työltä ja ikäviltä teknisiltä yllätyksiltä. Suunnittelutyössä on hyvä huomioida myös tekstitykseen kuluva aika, jota kannattaa varata 5-Io-kertaisesti videon kestoon nähden. Raadin kokemusten perusteella tekstitykseen saattaa hurahtaa pidempäänkin: tunnin mittaiseen videoon jopa kaksi työpäivää.

\section{Vertailtavat työkalut}

Valitsimme vertailuun monissa kotimaisissa organisaatioissa käytössä olevia työkaluja, joista useimpia käytetään myös muuhun kuin tekstitysten tuottamiseen, esimerkiksi videon editoimiseen, julkaisemiseen tai näytön tallentamiseen. Tarkasteluun valitut työkalut olivat YouTube, Screencast-O-Matic, Adobe Premiere Pro, Panopto ja Subtitle edit. Vertailussa keskityimme tekstityksen tuottamisen käyttökokemukseen ja siihen liittyviin ominaisuuksiin (ks. Tekstitystyökalujen vertailu -taulukko).

Tarkastelun ulkopuolelle jätettiin livetekstityksiä tarjoavat työkalut kuten PowerPoint ja Teams sekä Google Docsin puheesta tekstiksi -työkalu. Lisäksi rajasimme jutun ulkopuolelle kaupalliset suomen kieltä käsittelevät puheentunnistuksen ja tekstityksen kieliteknologiaratkaisut.

Vertailun tuloksia tarkasteltaessa on hyvä muistaa, että työkaluja on testattu ensisijaisesti Windows-käyttöjärjestelmällä ja yleisimmillä selaimilla: kaikkia mainittuja ominaisuuksia ei ole saatavilla esimerkiksi mobiiliversioissa. Lisäksi kukin testaaja on kokeillut vain osaa työkaluista, joten arviot nojaavat yksittäisten testaajien kokemuksiin.

Testatuista työkaluista maksuttomia ovat Youtube ja Subtitle edit. Screencast-O-Maticista on tarjolla maksuton versio, mutta sillä ei voi tekstittää. YouTubea, Panoptoa ja Subtitle editiä voi käyttää selaimella, muut työkalut vaativat asennuksen.

\section{Vertailun tulokset}

3.1 Automaattisen puheentunnistuksen toimivuus

Puheentunnistukseen perustuvaa automaattitekstitystä tarjoavat testatuista työkaluista YouTube, 
TEKSTITYSTYÖKALUJEN VERTAILU

\begin{tabular}{|c|c|c|c|c|c|}
\hline & Youtube Studio & Screencast-O-Matic & $\begin{array}{c}\text { Adobe } \\
\text { Premiere Pro }\end{array}$ & Panopto & Subtitle edit \\
\hline Maksullisuus & Maksuton & $\begin{array}{l}\text { Maksullinen, jos } \\
\text { haluaa tekstittää }\end{array}$ & Maksullinen & Maksullinen & Maksuton \\
\hline Käyttötarkoitus & $\begin{array}{l}\text { Videojulkaisu- } \\
\text { alusta }\end{array}$ & $\begin{array}{l}\text { Ruudunkaappaus/ } \\
\text { editointiohjelma }\end{array}$ & $\begin{array}{l}\text { Videoiden } \\
\text { editointi- } \\
\text { ohjelma }\end{array}$ & $\begin{array}{l}\text { Videojulkaisu- } \\
\text { alusta }\end{array}$ & Tekstitystyökalu \\
\hline $\begin{array}{l}\text { Tekniset } \\
\text { vaatimukset }\end{array}$ & Selain & $\begin{array}{l}\text { Windows, Mac, iOS, } \\
\text { Android, Chrome- } \\
\text { book }\end{array}$ & $\begin{array}{l}\text { Windows, } \\
\text { MacOS }\end{array}$ & $\begin{array}{l}\text { Windows, } \\
\text { MacOS, selain }\end{array}$ & $\begin{array}{l}\text { Windows, Linux, } \\
\text { selain }\end{array}$ \\
\hline $\begin{array}{l}\text { Automaatti- } \\
\text { tekstitys }\end{array}$ & Kyllä & Kyllä & $\mathrm{Ei}_{\mathrm{i}}$ & Kyllä & $\mathrm{Ei}_{\mathrm{i}}$ \\
\hline $\begin{array}{l}\text { Automaattiteks- } \\
\text { tiyksen kielet }\end{array}$ & $\begin{array}{l}\text { Esim. englan- } \\
\text { ti, ranska, saksa. } \\
\text { Suomi puuttuu. }\end{array}$ & $\begin{array}{l}\text { Esim. englanti, } \\
\text { suomi, ruotsi. }\end{array}$ & - & $\begin{array}{l}\text { Esim. englanti, } \\
\text { suomi, ruotsi. Or- } \\
\text { ganisaatiolla vain } \\
\text { yksi tekstityskieli. }\end{array}$ & - \\
\hline $\begin{array}{l}\text { Puheentunnis- } \\
\text { tuksen toimivuus }\end{array}$ & $\begin{array}{l}\text { Englanninkielinen } \\
\text { toimii hyvin. Suo- } \\
\text { menkielistä ei ole. } \\
\text { Tekstitys vaatii } \\
\text { jonkin verran kor- } \\
\text { jaamista. } \\
\text { Automaattiteks- } \\
\text { titys oikuttelee } \\
\text { välillä }\end{array}$ & $\begin{array}{l}\text { Selkosuomi toimii } \\
\text { hyvin, englanti vielä } \\
\text { paremmin. } \\
\text { Tekstitys vaatii kor- } \\
\text { jaamista. }\end{array}$ & - & $\begin{array}{l}\text { Puheentunnistus } \\
\text { toimii melko hyvin. } \\
\text { Tekstitys vaatii } \\
\text { melko paljon kor- } \\
\text { jaamista. }\end{array}$ & - \\
\hline $\begin{array}{l}\text { Open captions / } \\
\text { Closed captions }\end{array}$ & $\begin{array}{l}\text { Tekstitystyökalulla } \\
\text { vain closed capti- } \\
\text { ons, voi julkaista } \\
\text { open captions } \\
\text {-videotiedostoja }\end{array}$ & Molemmat & Molemmat & Molemmat & $\begin{array}{l}\text { Tekstitystyöka- } \\
\text { lulla vain clo- } \\
\text { sed captions, voi } \\
\text { julkaista open } \\
\text { captions - video- } \\
\text { tiedostoja }\end{array}$ \\
\hline $\begin{array}{l}\text { Tekstitystiedos- } \\
\text { toformaatit }\end{array}$ & $\begin{array}{l}\text { Esim. SubView } \\
\text { (.sbv), SubRip } \\
\text { Subtitle Format } \\
\text { (.srt) ja WebVTT } \\
\text { (. vtt). }\end{array}$ & $\begin{array}{l}\text { SubView (.sbv) ja } \\
\text { SubRip Subtitle For- } \\
\text { mat (.srt)- }\end{array}$ & $\begin{array}{l}\text { Esim. SubRip } \\
\text { Subtitle For- } \\
\text { mat (.srt). }\end{array}$ & $\begin{array}{l}\text { SubRip Subtit- } \\
\text { le Format (.srt), } \\
\text { ASHX (.ashx), } \\
\text { WebVTT (.vtt) ja } \\
\text { DXFP (.dxfp). }\end{array}$ & $\begin{array}{l}\text { Yli 280, esim. } \\
\text { SubRip Subtit- } \\
\text { le Format (.srt) } \\
\text { ja ja WebVTT } \\
\text { (.vtt). }\end{array}$ \\
\hline Käyttökokemus & Helppokäyttöinen & $\begin{array}{l}\text { Kohtuullisen help- } \\
\text { pokäyttöinen pienen } \\
\text { opettelun jälkeen. }\end{array}$ & $\begin{array}{l}\text { Vaatii paljon } \\
\text { opettelua }\end{array}$ & $\begin{array}{l}\text { Vaatii jonkin ver- } \\
\text { ran opettelua. }\end{array}$ & $\begin{array}{l}\text { Helppokäyttöi- } \\
\text { nen pienen opet- } \\
\text { telun jälkeen }\end{array}$ \\
\hline
\end{tabular}


Screencast-O-Matic ja Panopto. Adobe Premiere Prossa ja Subtitle editissä tekstitys on käsityötä, mutta niissä voi editoida toisessa ohjelmassa puheentunnistuksella tuotettua tekstitystiedostoa.

Suomenkielisen aineiston automaattitekstitykseen soveltuvat Screencast-O-Matic ja Panopto - jälkimmäinen tosin vain siinä tapauksessa, että organisaatiossa on valittu tekstityskieleksi suomi. Screencast-O-Matic tunnistaa selkosuomea kohtuullisen hyvin, mutta vapaampi tai murteellinen puhetyyli sekoittaa tekstityksen helposti.

Työkaluista YouTube pesee muut englanninkielisen aineiston automaattitekstityksen laadussa. Sen vuoksi onkin harmillista, että suomen kielen tunnistus puuttuu. YouTube saattaa myös joskus jättää videon tekstittämättä, ja tekstityksen luominen kestää pitkään etenkin pidemmissä tallenteissa.

Kaikki automaattitekstitystä tarjoavat työkalut jättävät jälkeensä korjailtavaa. Väliäännähdyksiä ja täytesanoja joutuu poistamaan, erisnimiä korjailemaan ja puhekieltä muuntamaan yleiskieliseksi.

Tekstittäjä joutuu yleensä lisäämään isot alkukirjaimet ja välimerkit käsin. Repliikkien pituutta voi joutua muuttamaan ja ruudulla näkyvää tekstiä pilkkomaan. Automaattitekstitys muuntaa puheen tekstiksi sitä paremmin, mitä käsikirjoitetumpaa ja artikuloidumpaa puhe on. Jos puhe on jo valmiiksi olemassa käsikirjoituksena, tekstitystä on myös helpompaa korjailla käsin leikkaa ja liimaa -menetelmällä.

Automaattitekstittäviä työkaluja käyttäessä on hyvä muistaa tietoturva: esimerkiksi Screencast-O-Matic käyttää Googlen puheentunnistuspalvelua, joten sitä ei suositella sensitiivisen tai luottamuksellisen aineiston tekstitykseen.

\subsection{Tekstityksen tekniset \\ ominaisuudet}

Testatuista työkaluista YouTube ja Subtitle edit tuottavat vain tiettyihin tiedostoformaatteihin sidottuja closed captions -tekstityksiä, jotka videon katsoja laittaa päälle tai pois päältä. Muissa työkaluissa tarjolla on myös videotiedostoon kiinni poltettava open captions -vaihtoehto. Adobe Premiere Pro -työkalussa on laajat mahdollisuudet muokata open captions -tekstitysten graafista ilmettä. Subtitle edit sopii hyvin tekstitystiedostojen konvertoimiseen formaatista toiseen.

YouTubessa, Screencast-O-Maticissa, Panoptossa ja Subtitle editissä tekstityksen muokkaaminen on helppoa. Koska YouTube ja Panopto ovat paitsi tekstitystyökaluja myös julkaisualustoja, niissä tuotettuja tekstityksiä on erityisen vaivatonta muokata. Jos taas Screencast-O-Maticissa, Adobe Premiere Prossa tai Subtitle editissä luotuja tekstityksiä haluaa muokata vaikkapa Youtuben julkaisualustalla, ne pitää viedä sinne erillisenä tiedos-

\section{Valitut puheentunnistuksen kömmähdykset}

Yhdistämiseen käytetään Boolen logiikkaa

$\rightarrow$ Yhdistämiseen käytetään puiden logiikkaa

Nykyisin oletushaku hakee

$\rightarrow$ Nykyisin oletus Saku hakee

Kolmannelle riville hyvinvointia vastaavat

$\rightarrow$ Kolmannelle riville hyvinvointi ja kova vatsa

Eeva Savolainen $\rightarrow$ Emma Silver Lining

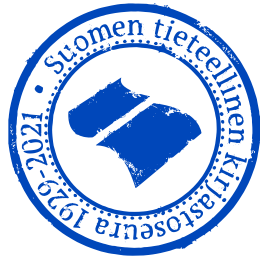


tona alustan hyväksymässä formaatissa (esimerkiksi .srt). Sen sijaan videoon poltettuja open captions -tekstejä ei voi enää julkaisualustalla muokata.

YouTubessa, Panoptossa ja Subtitle editissä tekstityksen ajastamisen muokkaaminen on kohtuullisen helppoa, kun taas Screencast-O-Maticissa se on hankalaa. Lisäksi Screencast-O-Maticissa tekstin ajastusta ei voi säätää itse, vaan tekstin on osuttava ohjelman antamiin paikkoihin. Yksi testaajista totesi YouTuben toiminnallisuuden tekstin ja videon synkronoinnissa olevan hieman kömpelö.

Kaikki työkalut mahdollistavat tekstityksen lataamisen tiedostona. Tämä voi olla hyödyllinen ominaisuus silloin, kun pääasiallisesti käytetty tekstitystyökalu ei jostakin syystä tuota automaattitekstitystä. Pulmatilanteissa voi muutenkin olla kätevää, että käytössä on useita työkaluja.

\section{Suomenkielinen puheentunnistus kehittyy}

- Suomenkielisen puheentunnistuksen laatu vaihtelee nykyisillä työkaluilla käyttökelpoisesta käyttökelvottomaan. Laatuun vaikuttavia tekijöitä ovat mm. äänisignaali ja puhujan puhetyyli.

- Puheentunnistuksen kehitystyössä on oleellista, että tekoälyllä on oppimisen pohjana riittävän laaja aineisto.

- Ratkaisuja on pyritty kehittämään useissa organisaatioissa ja hankkeissa, esim. Aaltoyliopistossa (Mikko Kurimon tutkimusryhmä), Helsingin yliopiston, Valtion kehitysyhtiö Vaken (nyk. Ilmastorahasto), Solitan ja Yleisradion yhteistyönä (Lahjoita puhetta-kampanja), Yleisradiossa (esim. MeMAD-hanke) ja useissa yrityksissä (esim. Lingsoft).

- CSC - Tieteen tietotekniikan keskus Oy osallistuu pohjoismaiseen speech-to-text -palvelun kilpailutukseen. Hankinnasta tulevat hyötymään myös suomalaiset korkeakoulut.

\subsection{Käyttökokemus}

Käyttökokemukseltaan Youtube on helpoin ja nopein omaksua, joten se on myös satunnaiskäyttäjälle hyvä valinta.

Screencast-O-Matic, Panopto ja Subtitle edit vaativat käyttäjältä jonkin verran opettelua. Panoptoa vaivaa paikoin heikko intuitiivisuus, Screencast-O-Matic saa puolestaan moitteita tekstityksen ja käyttöliittymän kömpelyydestä. Myös Subtitle editissä käyttöliittymä on melko karu, ja käytön kannalta oleellisiin määrityksiin ja komentoihin tutustuminen vie aikaa. Tekstitystyökaluna Subtitle edit voittaa kuitenkin esimerkiksi Screencast-O-Maticin ja soveltuu vaativaan käyttöön. Satunnaiskäyttäjälle Subtitle edit voi olla kuitenkin turhan mutkikas.

Myöskään Adobe Premiere Pro ei ole satunnaiskäyttäjälle paras vaihtoehto, sillä se vaatii testatuista ohjelmista käyttäjältään eniten paneutumista ja perehtymistä. Työkaluna se on kuitenkin monipuolinen ja toimii hyvin muiden Adoben ohjelmien kanssa. Ohjelman vahvuudet ovat myös sen heikkouksia: ominaisuuksia on paljon, mutta ohjelmaa on vaikea käyttää. Lisäksi ohjelma vaatii käyttäjän koneelta paljon tehoja.

\section{Raadin arvio}

Raadin suosikiksi työkaluista nousi helppokäyttöinen YouTube, jonka suuri ongelma on se, ettei se toistaiseksi tarjoa suomenkielistä automaattitekstitystä. 
Suomenkielisen puheentunnistuksen ansiosta kunniamaininnan saavat Screencast-O-Matic ja Panopto. Maksutonta tekstitystyökalua etsivälle Subtitle edit on potentiaalinen vaihtoehto. Adobe Premiere Prolle raati antaa maininnan "Graafikon valinta", mutta työkalu soveltuu lähinnä paljon videoita editoivalle käyttäjälle.

Raadin mielestä erityisesti suomen- kielisen puheentunnistuksen ansiot olivat testatuissa työkaluissa vielä maltillisia, sillä automatiikka osoittautui paikoin oikukkaaksi. Puheentunnistuksen kehittyminen tulee näyttämään suuntaa sille, mitkä tekstitysohjelmistot onnistuvat vakiinnuttamaan asemansa suomalaisissa organisaatioissa.

\section{Lähteitä ja lisälukemista}

Laki digitaalisten palvelujen tarjoamisesta I 5.3.2019/306

https://www.finlex.fi/fi/laki/alkup/2019/20190306

Laamanen, Merja \& Argillander, Teijo (2020): Automaattinen videon tekstitys

- kokemuksia ja hyviä käytänteitä. Pedaforum 2020 Abstraktikirja, s. 4I:

https://www.oulu.fi/sites/default/files/content/Abstractbook_Pedaforum2020_3.pdf

Ohjelmatekstityksen laatusuositukset. Kieliasiantuntijat ry 2020. https://kieliasiantuntijat. fi/wp/wp-content/uploads/202 I/or/Ohjelmatekstitysten_laatusuositukset_web-versio.pdf

Saavutettavasti.fi: https://www.saavutettavasti.fi/kuva-ja-aani/videot-ja-aanitteet/

Saavutettavuusvaatimukset.fi: https://www.saavutettavuusvaatimukset.fi/digipalvelulainvaatimukset/videoiden-ja-aanilahetysten-saavutettavuus/

Tampereen yliopiston IT-palvelujen käsikirja:

https://www.tuni.fi/it-palvelut/kasikirja/2743/I 5387?page= 19503

VÄNSKÄ, OlLI (202I): Suomessa tekoälyä koulutetaan kansanedustajien puheilla.

Mikrobitti 26. I. 202 I. https://www.mikrobitti.fi/uutiset/suomessa-tekoalya-koulutetaan-

kansanedustajien-puheilla/e3ccdaac-2732-46c3-9753-f64cd3c8feIf

\section{Kirjoittajat}

Riitta Holopainen

Itä-Suomen yliopisto

riitta.s.holopainen@uef.fi
LEENA JÄRVELÄINEN

Turun yliopisto

leena.jarvelainen@utu.fi
PärvikKi Karhula

Eduskunnan kirjasto

paivikki.karhula@eduskunta.fi

\author{
Eeva Savolainen \\ Aalto-yliopisto \\ eeva.savolainen@aalto.fi
}

\author{
Minna SUIKKa \\ Helsingin yliopisto \\ minna.suikka@helsinki.fi
}

Kiitokset

Emma Falck (csc), Emilia Ojala (Etelä-Suomen aluehallintovirasto), Aleksi Rossi (Yleisradio), Miikka Sipilä (Tampereen yliopisto) 